\title{
ADVANCEMENT OF NEW MATERIALS AND METHODS FOR ENHANCING THE QUALITY OF THE ENGINEERING PROCESS
}

\author{
Eny Kusrini ${ }^{1 *}$, Eko Adhi Setiawan ${ }^{2}$, Mohammed Ali Berawi ${ }^{3}$ \\ ${ }^{1}$ Department of Chemical Engineering, Faculty of Engineering, Universitas Indonesia, Kampus UI \\ Depok, Depok 16424, Indonesia \\ ${ }^{2}$ Department of Electrical Engineering, Faculty of Engineering, Universitas Indonesia, Kampus UI \\ Depok, Depok 16424, Indonesia \\ ${ }^{3}$ Department of Civil Engineering, Faculty of Engineering, Universitas Indonesia, Kampus UI Depok, \\ Depok 16424, Indonesia
}

The pursuit of new materials and engineering methods for energy sustainability has become an essential, exciting research issue. Various studies have been conducted to explore new materials and develop new engineering methods to process new material or re-use waste material for new energy resources. However, new materials cannot be used directly as sources of new energy; some of their characteristics need to be explored to determine their energy potentials. New engineering methods are also needed to process and prepare new materials, and advanced techniques are needed to pre-process new materials to remove unused residues that reduce their performance. Hence, finding new materials and innovating engineering methods to process them are inextricably linked topics.

Graphene is a particularly promising new material because of its extraordinary mechanical, electrical, thermal, and physical properties, providing many potential applications in various fields. Graphene is allotrope of carbon with two-dimensional crystal structure comprising planar sheets of $\mathrm{sp}^{2}$-bonded carbon atoms densely packed in a honeycomb crystal lattice. The chemical oxidation of graphite followed by its reduction has become the most potential method and economical process to produce graphene in bulk quantity. To utilize it in some industrial applications, such as a catalyst, an additive in water-based drilling fluid, and in advanced material technology, its dispersion is an important issue, since it is usually applied using solvent-assisted techniques, such as layer-by-layer assembly, spin-coating, and filtration. To disperse graphene well, chemical modifications can be applied on its surface to enhance the capability of graphene oxides to disperse in water, but the requisite oxygen-containing groups significantly decrease their electrical properties. To overcome this problem, other functional groups have been introduced to the graphene structure. Graphene can be functionalized with covalent and non-covalent modification techniques, both of which follow the surface modification by reduction. Thermal stability, reduced fluid loss, and lubricating capabilities are the main advantages of adding graphene to drilling fluid.

Other issues in many countries include the contamination of anions, such as fluoride, and heavy metal ions in groundwater, which varies by region based on availability, level of industrialization, and level of environmental responsibility. The concentration of fluoride anions in both surface water and groundwater has been rising in various parts of the world because of discarded effluents from semiconductors, electroplating, aluminum processing, the glass and ceramic industries, beryllium extraction, power plants, and water fluoridation. Therefore, it is essential for public safety to remove excessive fluoride anions from wastewater before discarding it into water streams, including drinking-water processing, assuring that the

\footnotetext{
${ }^{*}$ Corresponding author's email: ekusrini@che.ui.ac.id, Tel. 62-21-7863516 Ext. 204, Fax. 62-21-7863515 Permalink/DOI: https://doi.org/10.14716/ijtech.v10i6.3766
} 
concentration of fluoride in drinking water falls within acceptable levels. Many techniques have been reported to lower fluoride concentration in water, including membrane distillation, nanofiltration, chemical precipitation, reverse osmosis, electrodialysis, ion exchange, and adsorption. Among these methods, adsorption is the most well-known and the most appropriate for the removal of fluoride and/or heavy metal ions from waste water, making it indispensable to design, synthesize, and evaluate cost-effective adsorbents to efficiently remove anions and/or heavy metal ions from aqueous solutions.

Of many infrastructural approaches to implementing adsorption technology, smart grid are the most promising because efficient and advance technology. The implementation of smart grids in tropical areas is also important to discuss for further application in the world. Tropical weather, however, limits the application of smart grid technology. The characteristics and performance of renewable power generation in tropical areas, such as photovoltaic (PV) technology, is a topic that demands greater investigation. Different electricity tariff schemes have also become an exciting topic for this reason.

To address these limitations, the $4^{\text {th }}$ International Tropical Renewable Energy Conference (iTREC) 2019 was held on August 14-16, 2019 at the Anvaya Beach Resorts, Bali, Indonesia, proudly organized by the Tropical Renewable Energy Center, Faculty of Engineering, Universitas Indonesia. The central theme of this conference was "Sustainable Energy and Environment for Tropical Climate." An impressive 307 papers were presented from various countries, such as the United States, France, The Netherlands, Japan, Malaysia, Brunei Darussalam, Indonesia, Taiwan, Pakistan, Germany, Tunisia, and Turkey. The $4^{\text {th }}$ i-TREC 2019 covered six symposia: Smart Grid and Regulation, Bioenergy, Fuel Cell Technology, Energy Storage, Multifunctional and Advanced Materials, and Eco Tropical Built Environment. From 307 papers, we selected 20 papers for publication in International Journal of Technology (IJTech), which are summarized below.

The first paper by K. Kunaifi, A. Reinders, D. Kaharudin, A. Harmanto, and K. Mudiarto presented the actual performance of PV systems in Indonesia. This paper used 5-min resolution data from 2016 to 2018 from a 1-MW CIS and a $5 \mathrm{~kW}$ c-Si PV plant in West Java. The methodological approach included the performance analysis of these PV systems according to standard IEC 61724 and the investigation of degradation rates using NREL/RdTools. They made the following findings: the total annual Hi was $1500 \mathrm{kWh} / \mathrm{m}^{2}$ or around $4.2 \mathrm{kWh} / \mathrm{m}^{2}$ per day. The daily averaged performance ratio (PR) was $91.7 \% \pm 4 \%$ and $87.4 \% \pm 7 \%$, for the CIS system with string inverters and with a central inverter, respectively. The mean PR of the CIS systems was $12 \%$ higher than that of the c-Si system, which was $79.8 \%$. The final yield (Yf) of the CIS system was $3.85 \mathrm{kWh} / \mathrm{kWp}$, outperforming the c-Si system by $14 \%$. The CIS system degraded by $1.53 \%$ per year, which was lower than the c-Si system's degradation rate (Rd) of $3.72 \%$ per year. From these results, it can be concluded that, in this case, CIS technology performed better than c-Si in Indonesia's tropical climate.

The second paper by E. Kusrini, A. Suhrowati, A. Usman, V. Degirmenci, and M. Khalil examined the synthesis of graphite oxide, graphene oxide (GO), and reduced graphene oxide (rGO) from the spent pot lining (SPL) of aluminum industrial waste using a modified Hummers' method and zinc as the reducing agent. The effects of ultrasonication time from 1 to $2 \mathrm{~h}$ and $\mathrm{Zn}$ masses ranging from 8-24 $\mathrm{g}$ as reducing agents were observed in detail for the reduction reaction of GO into rGO. The chemical structures and morphology of the samples were confirmed through Fourier Transform Infrared (FTIR), Particle Size Distribution (PSD), Scanning Electronic Microscopy-Energy Dispersive X (SEM-EDS), and X-ray Diffraction (XRD) characterizations. The FTIR analysis confirmed the formation of GO. Although some restacking and unexfoliation of graphite structures showed a diffraction peak at $2 \theta$ of $26.54^{\circ}$, 
the XRD analysis exhibited a peak at $2 \theta$ of $20.04^{\circ}$, which was assigned to rGO after the reduction of GO. The smallest particle size of rGO graphene was observed in the range of 1-10 $\mu \mathrm{m}$ under an ultrasonication time of $1 \mathrm{~h}$ and with a $\mathrm{Zn}$ mass of $8 \mathrm{~g}$. The FTIR spectrum of GO showed a functional group double bond carbon $(\mathrm{C}=\mathrm{C})$, which was an indication of $\mathrm{rGO}$ formation due to the covalent bonding of the graphene structure. SEM image of the rGO showed that the morphology seemed thick and layer-stacking. The quality of rGO produced in this study needs further improvement, however, to meet requirements for applications.

The third paper by M.I.S. Tassakka, B.B. Islami, F.N.A Saragih, and C.R. Priadi discussed the suitability of food waste (FW) with an organic loading rate (OLR) of $8-14 \mathrm{kgVS} / \mathrm{m}^{3}$ per day to produce the highest volatile solids destruction (VSD) and methane. A semi-continuous, pilotscale dry $\mathrm{AD}$ of $0.5 \mathrm{~m}^{3}$ was operated for 134 days in mesophilic conditions. The results showed that the feedstock was suitable for dry AD due to high total solids (23.2-27.1\%) and organic content (volatile solids of $90-95 \%$ TS). The optimum OLR was $10 \mathrm{kgVS} / \mathrm{m}^{3}$ per day with a VSD of $92.2 \%$ and a methane yield of $127 \mathrm{LCH}_{4} / \mathrm{gVS}$ per day. Also, an OLR of $10 \mathrm{kgVS} / \mathrm{m}^{3}$ per day had the highest stability with a $\mathrm{pH}$ value of 6.52 and an ammonia concentration of 848 $\mathrm{mg} / \mathrm{l}$. The VSD value decreased with OLRs of $12 \mathrm{kgVS} / \mathrm{m}^{3}$ per day and $14 \mathrm{kgVS} / \mathrm{m}^{3}$ per day to $90.42 \%$ and $86.73 \%$, respectively.

The fourth paper by N. Aslfattahi, R. Saidur, M.F.M. Sabri, and A. Arifutzzaman conducted SEM to investigate the uniformity of synthesized, molten salt-based magnesium oxide nanoparticles. Differential scanning calorimetry (DSC) was used to perform enthalpy and melting-point measurements. The experimental results for solar salt-based $\mathrm{MgO}$ indicated a decrease in melting point and enthalpy by $7 \%$ and $12.4 \%$, respectively. The reduction of enthalpy expressed that, with the addition of magnesium oxide to solar salt, the final nanocomposite tends to have more exothermic reactions and enhanced thermal conductivity performance at the melting point. Lower melting points are one of the major concerns regarding molten salt-based nanofluids. $\mathrm{MgO}$ nanoparticles with a concentration of $5 \mathrm{wt} \%$ decrease the melting point by $7 \%$. Mass loss and thermal stability measurements were conducted using thermogravimetric analysis (TGA). The experimentally acquired results revealed an increment of decomposition temperature from $734.29-750.73^{\circ} \mathrm{C}$, proving the enhancement of thermal stability in high temperatures.

The fifth paper by A.S. Norazam, H.M. Kamar, N. Kamsah, and M.I. Alhamid determined the moisture removal capacity (MRC), thermal effectiveness $\left(\varepsilon_{\text {th }}\right)$, and dehumidification effectiveness $\left(\varepsilon_{\mathrm{DW}}\right)$ of a solid desiccant wheel material using a numerical method. A representative three-dimensional model of an air channel enclosed with desiccant material was developed and meshed using triangular elements. Flow simulations were carried out under a transient condition. The model was validated by comparing the simulation results of moisture content and air temperature at the outlet of the air channel with similar experimental data obtained from the literature. The relative errors of the desorption process were found to be $0.14 \%$ for air temperature and $3.7 \%$ for air humidity. For the adsorption process, the errors were around $3.2 \%$ and $0.01 \%$, respectively. The results indicated that the numerical model estimated the desiccant material performance well and that, at any given regeneration temperature, gel$\mathrm{CaCl}_{2}$ had the highest $\mathrm{MRC}$, dehumidification, and thermal effectiveness compared to silica gel $\mathrm{B}$ and Zeolite $13 \mathrm{X}$.

The sixth paper by N.Z.A. Daud, B.N.M. Said, F. Ja'afar, H.M. Yasin, E. Kusrini, and A. Usman investigated the utilization of Citrus maxima for the isolation of pectin under acidified conditions using L-(+)-tartaric acid at an extraction $\mathrm{pH}$ bewteen 1.0 and 2.0. The extraction yield and physicochemical properties (ash content, equivalent weight, methoxy content, anhydrouronic acid, and degree of esterification) of the isolated pectin were investigated. The 
highest yield $(70.2 \%)$ obtained in this extraction was at $\mathrm{pH} 1.0,60^{\circ} \mathrm{C}$, and 120 mins. The optimized condition of the isolated pectin in this study was based on yield and physicochemical properties, where pectin extracted at $\mathrm{pH} 2.0$ and $60-80^{\circ} \mathrm{C}$ for $60-120$ min resulted a $59.6 \%$ yield with low ash content $(2.82 \%)$, the highest equivalent weight $(1098.8)$ for the gelling effect, and the highest DE (39.2\%). The findings were within the range for high-quality pectin. The FTIR spectra of the isolated pectin at different $\mathrm{pH}$ media at a constant temperature of $70^{\circ} \mathrm{C}$ and an extraction time of 60 min were compared. The presence of methyl-esterified carboxyl at a frequency of $1696 \mathrm{~cm}^{-1}$ and a carboxylate group confirmed the presence of pectin.

The seventh paper by W. Hong, K. Ibrahim, and S-C. Loo discussed the challenges of green retrofit implementation in Malaysian office buildings. This paper aimed to review the focus and direction of green development in the Malaysian construction industry and subsequently propose a research agenda for the rapid adoption of green facade retrofitting in local office buildings. The research agenda proposed first surveying the key factors that impede the uptake of green facade retrofitting followed by conducting energy simulations of contemporary green facade technologies (GFTs) using BIM software. It also proposed developing a decisionmaking tool for GFT selection based on the simulated energy performance data and critical factors associated with building owners' considerations and expectations. The final research output is expected to spur green development progress by identifying the real issues faced by green retrofitting in the contemporary Malaysian construction industry.

The eighth paper by M.A. Berawi, N. Suwartha, F. Salsabila, Gunawan, P. Miraj, and R. Woodhead presented works about the impact of the LRT Jabodebek project on the costs of commercial properties and other influencing variables. The authors collected the property data around the South Jakarta and Jabodebek stations as well as other variables capable of affecting prices. Approximately $13 \%$ of the commercial property analyzed was spread over a distance of $1 \mathrm{~km}$ from the LRT station. The paper showed that the distance from the stations had no impact on property prices.

The ninth paper by M.N.H. Rozaini, B. S., M.R. Ramachandran, and E.A. Kadir demonstrated how advanced materials such as graphene, molecularly imprinted polymers (MIPs), and polymeric cyclodextrins were used as adsorbents for the determination of contaminants, such as bisphenol A, steroids, sulfonamide antibiotics, and antimicrobial agents. These adsorbents were essential components of the micro-solid phase extraction used for the pretreatment of the sample. It briefly introduced the adsorbents studied and explained the evolution of extractions. Finally, it highlighted distinctive features of the analytical methods for real sample analysis of the contaminants.

The tenth paper by A.T. Yuliansyah, C.O. Putri, B.D. Clarasinta, and M. Nonaka discussed gasification as one of the possible methods for producing cleaner fuel from biomass, arguing that the gasification approach can handle a wide range of inhomogeneous biomasses (including forest, agricultural, and organic processing residues) and convert them into homogeneous gases with a considerably higher level of applicability. The paper also investigated the effect of hydrothermal treatment on the gasification process of biomass waste, showing that the $\mathrm{CO}$ yield steadily increased proportionally with the increase of hydrothermal treatment temperature. They summarized their results by stating that hydrothermal treatment is a promising method to achieve more efficient gasification of biomass waste that might also be applicable to the gasification of other biomass resources.

The eleventh paper by S. Sukarni, S. Sumarli, I.M. Nauri, A. Prasetiyo, and P. Puspitasari discussed the thermal behavior of Spirulina platensis (SP) characteristics during combustion in the presence of $\mathrm{MgCO}_{3}$ and $\mathrm{Al}_{2} \mathrm{O}_{3}$ additives. The samples in their study were pure $\mathrm{SP}$ and mixtures of SP and additives in mass fractions of 0.3, 0.6, and $0.9 \mathrm{wt} \%$. Samples of $10 \mathrm{mg}$ were 
mounted to the thermobalance and subjected to a furnace at $10^{\circ} \mathrm{C} / \mathrm{min}$. The $100 \mathrm{~mL} / \mathrm{min}$ air atmosphere continuously varied during the combustion process from $30-1200^{\circ} \mathrm{C}$. Thermogravimetric (TG) and derivative thermogravimetric (DTG) curves were used to characterize the thermal behaviors of the samples. The Horowitz-Metzger method was utilized to evaluate the impacts of additives on the kinetic parameters of the samples. The results of their experiments indicated that the presence of additives mainly affected the main decomposition stages at lower temperatures.

The twelfth paper by M.A. Berawi, P.L. Wicaksono, Gunawan, P. Miraj, and H.A. Rahman discussed the financial feasibility of transit-oriented development (TOD) on the LRT. The initial and operational maintenance costs were used as a case study after reviewing the relevant journal literature regarding the amount needed to develop TOD elsewhere. They acquired revenue amounts using a dynamic system. From this study, the initial cost of LRT and property

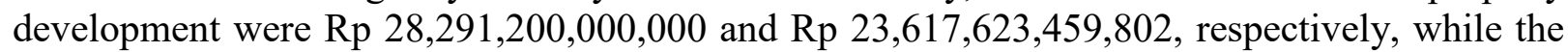
operation and maintenance costs were Rp 19,017,051,414,153 and Rp 36,953,818,402,363, respectively. However, the new revenue obtained from operating LRT stations and properties are $\mathrm{Rp} 41,109,405,822,615$ and $\mathrm{Rp} 150,524,288,553,165$ with an IRR value of $9.75 \%$. The values of WACC below $11.01 \%$ indicated that the project is not financially feasible.

The thirteenth paper by E.A. Setiawan, A. Prakoso, and V. Maulia presented the design of dynamic pricing schemes to be implemented in Indonesia. The authors argued that the standard dynamic pricing scheme already implemented by the western region may not apply to Indonesia. They observed the characteristics of the designed dynamic pricing and compared them to the characteristics of the load. The designed dynamic pricing in this paper combined critical peak pricing (CPP) and time-of-use (ToU) schemes.

The fourteenth paper by A.S. Kusumah, I.I. Hakim, R. Sukarno, F.F. Rachman, and N. Putra examined the use of a U-shaped heat pipe heat exchanger (HPHE) to recover exhaust air heat from the indoor room of an HVAC system. The U-shaped HPHE consisted of several tubular, U-shaped heat pipes with water as a working fluid arranged in a staggered configuration. Tests were carried out to find the effects of the inlet air temperature, air velocity, and the number of heat pipes on the system's effectiveness. The experiment showed that the higher the temperature of the inlet air, the more effective the U-shaped HPHE was. The capacity of the cooling system was thus increased.

The fifteenth paper by A. Wahid and W.R. Utomo discussed the usage of a multi-variable model predictive control (MMPC) to control the dimethyl ether (DME) purification process of methanol in the production of DME from synthesized gas. They considered the utilization of MMPC $(4 \times 4)$ to address the four input variables and four output variables of the process. The inter-variable interaction was shown in a $4 \times 4$ matrix, each matrix element being the first order plus dead-time (FOPDT) model. MMPC $(4 \times 4)$ was tested by changing the setpoint (SP) and disturbance rejection. The control performance indicators used were the integral of absolute error (IAE) and the integral of square error (ISE) and, as a comparison, the control performance of single-input single-output (SISO) model predictive control (MPC). The results showed that MMPC $(4 \times 4)$ was better than MPC in both IAE and ISE. In SP change, MMPC $(4 \times 4)$ improved the control performance of MPC, significantly, by $78 \%$ (IAE) and $90 \%$ (ISE), whereas in disturbance rejection testing, the improvement of control performance was $58 \%$ (IAE) and $81 \%$ (ISE).

The sixteenth paper by R.P.S. Wicaksono, S.H. Fathia, I.F. Kolang, A. Riadi, W. Nirbito, Y. Muharam, and Y.S. Nugroho examined controlling the temperature of coal using a heat exchanger placed on a coal pile and then flowed with water. This paper investigated the effect of the ratio of the heat transfer surface area and the volume of combustible material on the 
effectiveness of temperature control in spontaneous combustion prevention. A laboratory-scale experiment was set up to control the temperature of the coal pile using a heat exchanger made from copper tubes. Coal samples were placed in cylindrical containers with diameters of $8.5 \mathrm{~cm}$ and heights of $11 \mathrm{~cm}$. A spiral-shaped heat exchanger was then placed in the center of the cylindrical container and flowed with seawater at an approximate temperature of $27^{\circ} \mathrm{C}$. Tests were carried out using several configurations of heat exchanger dimensions to determine the effect of the ratio of heat transfer surface area and volume of combustible material. The test results showed that greater surface areas of heat transfer produced higher cooling load and temperature difference.

The seventeenth paper by B. Prabowo, F.S.H. Simanjuntak, Z.S. Saldi, Y. Samyudia and I.J. Widjojo, discussed technical and economic assessments on the implementation of waste to energy (WTE) technology in Indonesia. The technical assessment was conducted by investigating the chemical and physical properties of MSW, resulting in a comprehensive review of the technical feasibility and expected output of applying the treatment technologies. The economic assessment was conducted by simulating a business model of 1000 Tons-per-day WTE facility that satisfies some sets of economic parameters. For the case study, the authors select two types of waste quality: (1) Low calorific value MSW, $6860 \mathrm{KJ} / \mathrm{Kg}$-as received, taken from the municipal temporary waste collection station in South Tangerang City; and (2) High calorific value MSW, $8970 \mathrm{MJ} / \mathrm{Kg}$-as-received, taken from the temporary waste collection in a Residential Apartment in Jakarta City. The result of their experiments shows that the reduction of set pricing to either IDR 400,000/tons for a tipping fee or IDR 1,350 for electricity might still satisfy the minimum limit of the set parameter.

The eighteenth paper by N. Sofyan, A. Ridhova, M.C. Sianturi, and A.H. Yuwono discussed the effect of $\mathrm{NaCl}$ on the crystal growth of nano rosette $\mathrm{TiO}_{2}$ hydrothermally on a glass substrate. Nano rosette $\mathrm{TiO}_{2}$ was synthesized through deposition on top of a glass substrate via hydrothermal reaction at $170^{\circ} \mathrm{C}$ for $6 \mathrm{~h}$. The effect of $\mathrm{NaCl}$ on nano rosette $\mathrm{TiO}_{2}$ crystal growth during the hydrothermal process was observed through the addition of different concentrations of $\mathrm{NaCl}(0 \%, 2.5 \%, 5 \%$, and $10 \% \mathrm{v} / \mathrm{v})$ to the mixture of precursors. The formation and growth of the crystal were characterized using X-ray diffraction, whereas the morphology was examined using an SEM. The X-ray diffractogram revealed that the crystal belonged to rutile $\mathrm{P} 42 / \mathrm{mnm}$ with lattice parameters of $\mathrm{a}=4.557(6) \AA$ and $\mathrm{c}=2.940(5) \AA$. The morphology of the reaction product showed that the addition of $\mathrm{NaCl}$ inhibited the crystal growth of nano rosette $\mathrm{TiO}_{2}$ with an average rosette petal cross-sectional size $80 \%$ smaller than that of the crystal grown with no added $\mathrm{NaCl}$.

The nineteenth paper by E. Kusrini, S. Wu, B.H. Susanto, M. Lukita, M. Gozan, M.D. Hans, A. Rahman, V. Degirmenci, and A. Usman investigated the effects of acid/base activation and chitosan coating on clinoptilolite zeolite as an adsorbent for biogas purification from palm oil mill effluent (POME) using simultaneous absorption-adsorption methods. The effects of chitosan concentration on the clinoptilolite zeolite/chitosan (ZAC) composites were studied to determine the best type of adsorbent for purifying biogas to obtain the highest methane $\left(\mathrm{CH}_{4}\right)$ concentration. The biogas produced from POME via an anaerobic digestion process had a $\mathrm{CH}_{4}$ concentration of $87 \%$ and a carbon dioxide $\left(\mathrm{CO}_{2}\right)$ concentration of $13 \%$. ZAC was used as the adsorbent in the adsorption process, and the $\mathrm{Ca}(\mathrm{OH})_{2}$ solution was used for the absorption process. To enhance the efficiency of the adsorbent when purifying biogas, clinoptilolite zeolite (ZA) was activated using a strong acid $(\mathrm{HCl})$ and base $(\mathrm{NaOH})$ in various concentrations (ranging from $1-3 \mathrm{M}$ ), calcination at $450^{\circ} \mathrm{C}$ for $2 \mathrm{~h}$, and coating with chitosan concentrations (ranging from $0.25-1 \mathrm{v} / \mathrm{v} \%$ ). The ZA was coated with chitosan to increase its adsorption efficiency, as chitosan contains high levels of amine and hydroxyl compounds that interact with $\mathrm{CO}_{2}$ impurities and form carbamic acid, ultimately producing carbamate salt. The final content 
of the biogas after the purification process with absorption using the $\mathrm{Ca}(\mathrm{OH})_{2}$ solution and adsorption in a fixed-bed column using the ZAC 2-0.5 composite was $0.42 \% \mathrm{CO}_{2}$ and $99.58 \%$ $\mathrm{CH}_{4}$. The purified biogas had a very high methane gas content; thus, this study's findings suggested that purified biogas can be used as a clean energy source for wider industrial applications.

The twentieth paper by A. Arifutzzaman, A.F. Ismail, M.Z. Alam, A.A. Khan, and R. Saidur investigated the extraction of exfoliated graphene concentration yields and compared estimated percentage concentrations of exfoliated graphene between organic solvents and deionized water. Exfoliated graphene from two different organic solvents, N-Methyl-2-Pyrrolidone (NMP) and N-dimethylformamide (DMF), were taken. The extraction of exfoliated graphene was conducted by membrane filter using a vacuum filtration system. The concentration of exfoliated graphene solvents was estimated using Beer's law by preparing separate standard graphs. The result of their experiments showed the few layers of graphene in the sonicationassisted liquid-phase exfoliated graphene in both organic solvents, NMP and DMF. Very slight levels of aggregation and sedimentation appeared within 30 days after centrifugation.

We hope this special edition of IJTech provides useful research findings and insight that lead to new knowledge. We invite you to join us in this journal by sending your research for consideration.

With warmest regards from Jakarta,

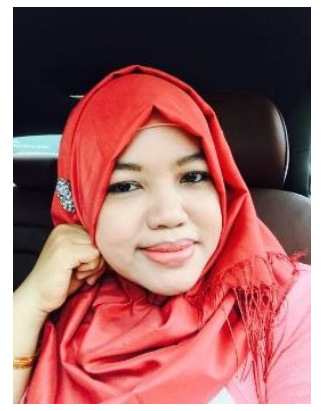

Dr. Eny Kusrini, S.Si Editorial Board Member

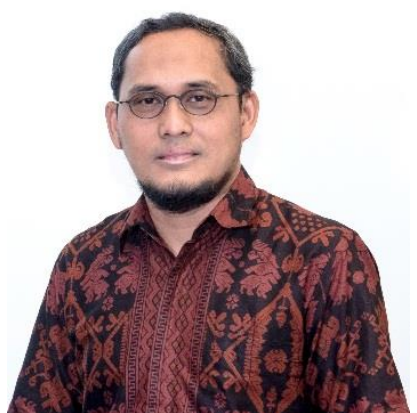

Dr. Ing. Eko Adhi Setiawan, ST., MT Editorial Board Member

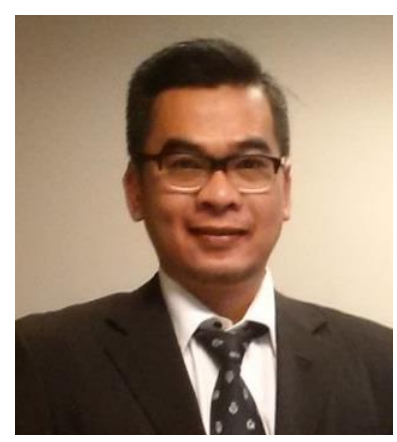

Dr. Mohammed Ali Berawi

Editor in Chief 